\title{
When too much of a novel thing may be what's "bad": commentary on Fisher, Godwin, and Seltman (2014)
}

\author{
Kana Imuta ${ }^{1 *}$ and Damian Scarf ${ }^{2}$ \\ 'School of Psychology, University of Queensland, Brisbane, QLD, Australia \\ ${ }^{2}$ Department of Psychology, University of Otago, Dunedin, New Zealand \\ ${ }^{*}$ Correspondence: k.imuta@uq.edu.au
}

Edited by:

Yusuke Moriguchi, Joetsu University of Education, Japan

Reviewed by:

David J. Lewkowicz, Northeastern University, USA

Keywords: classroom environment, attention, novelty response, children's education, children, learning and memory

\section{A commentary on}

Visual environment, attention allocation, and learning in young children: when too much of a good thing may be bad

by Fisher, A. V., Godwin, K. E., and Seltman, H. (2014). Psychol. Sci. 25, 1362-1370. doi: 10.1177/095679761453 3801

Young children's classrooms are often filled with colorful decorations. In their recent article, Fisher et al. (2014a) present evidence that these decorations may be detrimental to children's learning. Specifically, children were less likely to stay focused, and attained lower test scores, when experimental lessons were given in a "decorated classroom" compared to a "sparse classroom." Furthermore, children's test scores were negatively correlated with the amount of time that they were distracted, suggesting a direct relationship between these two variables. Fisher et al. (2014a) concluded that "colorful visual displays may promote off-task behavior in young children, resulting in reduced learning opportunities and achievement" (p. 1368). Is too much of a good thing bad? We argue here that, perhaps, only when the good things are all too novel.

Fisher et al. (2014a) suggest that extraneous visual stimuli compete for children's attention, causing distraction and impair performance on cognitive tasks. Rather than the irrelevance of the visual displays, however, it may have been the novelty that detracted children's attention away from the lesson to the environment. Indeed, Fisher et al.'s (2014a) decorated classroom was a laboratory room, purposefully adorned with a large amount of novel and colorful displays. Their sparse classroom, on the other hand, was the same room, but with all of these novel displays removed. It is well-established that novelty has powerful effects on children's attention allocation; in fact, some of the most well-established empirical procedures that are used to study early cognitive development rely on children's preference to attend to novel stimuli (Hayne, 2004). Fisher et al. (2014a) briefly allude to the issue of novelty in their Discussion, however, suggest that this cannot account for their findings.

Specifically, in their Discussion, Fisher et al. (2014a) cites another one of their studies in which children were given lessons in a decorated classroom for 2 weeks and, when compared to behavior in the sparse classroom, children were distracted for a greater amount of time in the decorated classroom on both Weeks 1 and 2 (Godwin and Fisher, 2012). Fisher et al. (2014a) did not acknowledge, however, that the proportion of time that children spent attending to the decorated environment decreased significantly between Weeks 1 and 2; that is, children exhibited habituation to the environment (Godwin and Fisher, 2012). If this is the case, classroom decorations may only have a transient impact on children's attention.

In their analysis, Fisher et al. (2014a) collapsed across the three lessons children spent in each classroom, potentially masking any habituation that may have occurred. To investigate this possibility, we reanalyzed their data (Fisher et al., 2014b). We used two methods to accommodate the fact that $8(33 \%)$ children missed at least one of the six lessons: First, we conducted the ANOVA with list-wise deletion, such that only the 16 children with complete data sets were included. Second, we used the data imputation procedure in SPSS to replace missing data, such that all 24 children could be included in the analysis. Both methods resulted in identical pattern of results, so here we report only the outcomes from the former. Condition, $F_{(1,15)}=53.16, p<0.001$, $\eta^{2}=0.78$, and Lesson, $F_{(2,30)}=5.59$, $p=0.009, \quad \eta^{2}=0.27$, were significant and qualified by a Condition $\times$ Lesson interaction, $F_{(2,30)}=12.80, p<0.001$, $\eta^{2}=0.46$. To investigate the interaction, separate One-Way ANOVAs were conducted for each condition with Lesson as a repeated measure. Lesson was significant for both the Sparse, $F_{(2,30)}=8.07$, $p=0.002, \eta^{2}=0.35$, and Decorated, $F_{(2,30)}=9.18, \quad p=0.001, \quad \eta^{2}=0.38$, conditions. As shown in Figure 1, the percentage of time that children were distracted by the environment increased slightly across lessons in the sparse classroom. More importantly, consistent with the idea that children may habituate to a decorated classroom, the percentage of time that children were distracted by the environment decreased considerably across lessons in the decorated classroom.

On one hand, the lack of habituation between Lessons 2 and 3 in the decorated classroom suggests that, even with greater exposure, no further habituation will 


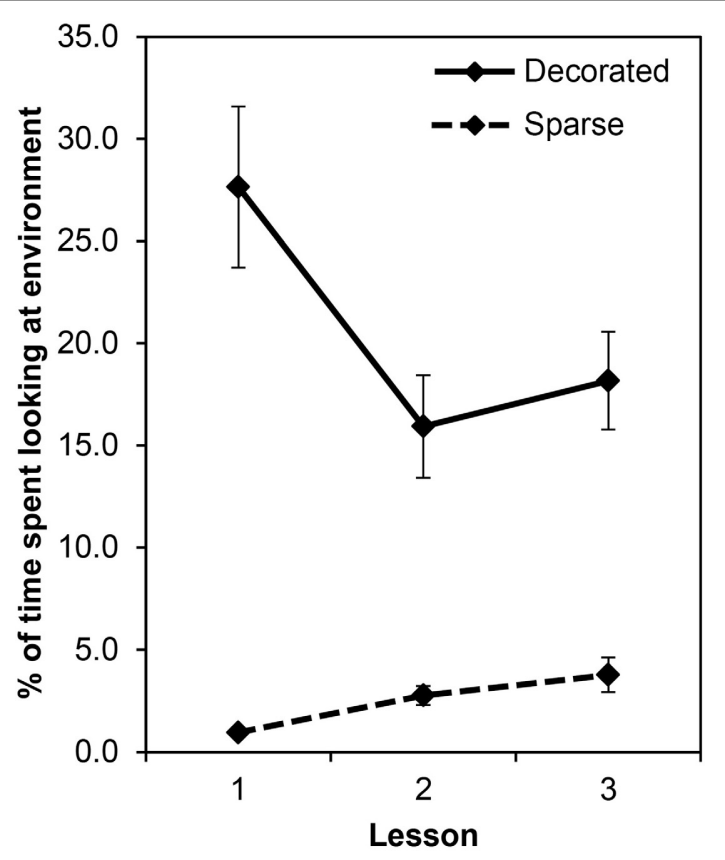

FIGURE 1 | Percentage of time that Fisher et al.'s (2014b) children spent looking at the classroom environment during their first, second, and third lessons in the "decorated" and "sparse" classrooms.

occur; however, we think this is unlikely for two reasons. First, children only spent approximately three 15 -min sessions in each classroom, dispersed across a 2 -week period. To put this into context, the $45 \mathrm{~min}$ children spent in each classroom represents, at most, just $25 \%$ of a half day $(\sim 3 \mathrm{~h})$ and $13 \%$ of a full day $(\sim 6 \mathrm{~h})$ of kindergarten, or 5 and $3 \%$ of a 5 -day kindergarten week, respectively. Given this, the level of distraction displayed by children in Lessons 2 and 3 is likely not reflective of what one would observe in an actual kindergarten setting. Second, in another one of Fisher and colleagues' previous studies that assessed children's on- and off-task behaviors in actual elementary school classrooms, they reported that children spent just $4.6 \%$ of their time attending to the environment (Godwin et al., 2013). This level of distraction is essentially identical to that displayed by children in the sparse classroom in Lesson $3(M=$ $4.7 \%$ ), and supports our speculation that further habituation would have occurred, had the children in Fisher et al.'s (2014a) study spent more time in the decorated classroom. Keeping this in mind, however, we also acknowledge that at least within the scope of Fisher et al.'s (2014b) data, condition differences remained at Lesson 3. We propose, therefore, that our novelty hypothesis and Fisher et al.'s (2014a) irrelevance hypothesis may not be mutually exclusive.

Beyond a momentary distraction, classroom decorations may actually be beneficial in the long run. For example, allowing children to decorate the classroom with their own work may improve their self-esteem and beliefs about the value of their work (Maxwell and Chmielewski, 2008). Also, when classroom decorations are related to what the children are learning, the decorations may act as "reminder" cues, improving children's long-term memory of educational information (Hayne, 2004). Taken together, when considering the valuable question of how to optimize the classroom visual environment, we should consider how the relevance as well as the novelty of the visual displays interact to influence children's learning outcomes.

\section{ACKNOWLEDGMENT}

We would like to thank Associate Professor Anna Fisher for her valuable comments to the original draft of our manuscript.

\section{REFERENCES}

Fisher, A. V., Godwin, K. E., and Seltman, H. (2014a). Visual environment, attention allocation, and learning in young children: when too much of a good thing may be bad. Psychol. Sci. 25, 1362-1370. doi: 10.1177/095679761 4533801

Fisher, A. V., Godwin, K. E., and Seltman, H. (2014b). Data from: Visual Environment, Attention Allocation, and Learning in Young Children: When too Much of a Good Thing May be Bad. Dryad Digital Repository. doi: 10.5061/dryad. d 2441

Godwin, K. E., Almeda, M. V., Petroccia, M., Baker, R. S., and Fisher, A. V. (2013). "Classroom activities and off-task behavior in elementary school children," in Proceedings of the 35th Annual Meeting of the Cognitive Science Society (Berlin), 2428-2433.

Godwin, K. E., and Fisher, A. V. (2012). Do young children habituate to their classroom environment? in Paper Presented at the 34th Annual Conference of the Cognitive Science Society, (Sapporo).

Hayne, H. (2004). Infant memory development: implications for childhood amnesia. Dev. Rev. 24, 33-73. doi: 10.1016/j.dr.2003. 09.007

Maxwell, L. E., and Chmielewski, E. J. (2008). Environmental personalization and elementary school children's self-esteem. J. Environ. Psychol. 28, 143-153. doi: 10.1016/j.jenvp.2007. 10.009

Conflict of Interest Statement: The authors declare that the research was conducted in the absence of any commercial or financial relationships that could be construed as a potential conflict of interest.

Received: 20 August 2014; accepted: 26 November 2014; published online: 23 December 2014.

Citation: Imuta K and Scarf D (2014) When too much of a novel thing may be what's "bad": commentary on Fisher, Godwin, and Seltman (2014). Front. Psychol. 5:1444. doi: 10.3389/fpsyg.2014.01444

This article was submitted to Developmental Psychology, a section of the journal Frontiers in Psychology. Copyright (c) 2014 Imuta and Scarf. This is an openaccess article distributed under the terms of the Creative Commons Attribution License (CC BY). The use, distribution or reproduction in other forums is permitted, provided the original author(s) or licensor are credited and that the original publication in this journal is cited, in accordance with accepted academic practice. No use, distribution or reproduction is permitted which does not comply with these terms. 